\title{
The International Competitive Relationships of Three Leading Countries in the Global Shipbuilding Industry
}

\author{
Inyoung Hwang* and J. Hun Park**
}

\begin{abstract}
South Korea, China, and Japan are three dominant countries in the global shipbuilding industry, and the competition between them has become more complex over time. The International Maritime Organization environmental regulations and the wave of Industry 4.0 have made the global shipbuilding industry more technology intensive than before. However, after the financial crisis of 2008, China's labor-intensive strategy outperformed the technology-intensive competitive strategy adopted by Japan and South Korea, and China was ranked first with the largest market share. This study sets out to explore whether China's labor-intensive strategy will remain superior to the technology-intensive one of Japan and South Korea. Specifically, we investigate how competitive relationships between the three countries changed after the 2008 global financial crisis. We also forecast how many ships each country will complete in through 2026. To analyze this dynamic competitive system, we use the three-dimensional Lotka-Volterra model, drawing on annual data reporting the number of ships built. The findings suggest that China has gained a competitive advantage over Japan since the 2008 global financial crisis, while South Korea has maintained a mutualistic relationship with both Japan and China. Our forecast suggests that China may lose its competitive advantage in the near future, if China does not embrace a more technology-intensive approach.
\end{abstract}

Keywords: competitive relationships, Lotka-Volterra model, shipbuilding industry, industrial policy.

* Inyoung Hwang is a visiting scholar in the School of Public Affairs at Arizona State University. E-mail: iyhwang929@gmail.com.

** J. Hun Park, corresponding author, is a professor in the Graduate School of Public Administration at Seoul National University and adjunct researcher at the Korea Institute of Public Affairs. E-mail: dearpark@snu.ac.kr.

Manuscript received October 24, 2018; out for review October 31, 2017; review completed November 29, 2017; accepted December 3, 2018.

The Korean Journal of Policy Studies, Vol. 33, No. 3 (2018), pp. 73-91.

(C) 2018 by the GSPA, Seoul National University 


\section{INTRODUCTION}

Since the 1980s, Japan and South Korea have accounted for the majority of the market share in the global shipbuilding industry. Shipbuilding has been a major industrial sector in both countries, and their governments have strategically it. After the 2008 global financial crisis, however, China emerged as a top player in the global shipbuilding industry, especially in the bulk carrier and tanker sectors, which it achieved by cost competitiveness. China plans to make shipbuilding a key industry by raising its proportion of the global market to $40 \%$ by 2020 . Japan and South Korea are trying to catch up with China by concentrating on high value-added ships (Jiang, Bastiansen, \& Strandenes, 2013).

Both Japan and South Korea have high levels of technological capabilities for shipbuilding; China, on the other hand, has a significant technology gap but also has an advantage when it comes to labor costs compared to both countries. According to the Korea Development Bank (2018), South Korea has the highest level of R\&D capacity, and Japan has the highest level of equipment and materials technology, while China has a relatively low R\&D capacity. There is approximately fiveyear technology gap between China and the other two leading countries (Korea Development Bank, 2018). However, the salary level in China is four times lower than that in South Korea and Japan, and it has the advantage that new workers enter the labor force constantly, unlike in South Korea and Japan, which have suffered chronic labor shortage (Korea Development Bank, 2018). These characteristics imply that the shipbuilding industry in Japan and South Korea is technology intensive while the shipbuilding industry in China is relatively labor intensive.

Its rapid growth after the 2008 financial crisis shows that China's labor-intensive strategy has been successful so far in the global market. However, it is uncertain whether China will continue to reign in the global market by maintaining its current labor-intensive strategy in this changing industry. Although shipbuilding has long been a labor-intensive industry, it is rapidly transforming into a technology-intensive industry due to an increased demand for high value-added ships such as those that transport liquefied natural gas. In addition, all shipbuilding companies must meet the high environmental standards of the Energy Efficiency Design Index that the International Maritime Organization. R\&D investment in ecoships with improved fuel efficiency that do minimal harm to the environment has increased. $R \& D$ investment in smart ships has also increased in line with the latest manufacturing trend, Industry 4.0 , which merges information technology with manufacturing.

In this context, the question can be raised of whether China's labor-intensive 
strategy will be still superior to Japan and South Korea's technology-intensive strategy in the future. Specifically, this study seeks to find answers to the following two questions. How did competitive relationships in the global shipbuilding industry between Japan, South Korea and China change in the rapidly changing circumstances after the financial crisis of 2008? What country is likely to be the most dominant of the three leading countries in the future? Evaluating competitive relationships and forecasting the performance of these three leading countries may provide some important insights about dominant strategy in the global shipbuilding industry.

To examine the dynamics of competition among Japan, South Korea, and China in the global shipbuilding industry, this study adopts a three-dimensional Lotka-Volterra model, drawing on annual longitudinal data of shipbuilding completion. Zhang and Lam (2013) suggest use the Lotka-Volterra model to analyze the maritime industry; however, this approach has not yet been applied to ocean industries. This study contributes to this growing area of research by exploring the complex dynamics of competition in the global shipbuilding industry.

\section{MODEL DESCRIPTION AND DATA}

\section{Lotka-Volterra Model}

The Lotka-Volterra model is a simultaneous ordinary differential equations model of mathematical biology based on the predator-prey system proposed by Alfred Lotka (1925). Researchers have long argued that the Lotka-Volterra model is a useful tool in explaining human behavior (Goodwin, 1967; Samuelson, 1971; Samuelson, 1974, Karmeshu, Bhargava, \& Jain, 1985; Bhargava, 1989). This model was initially used to estimate population size and in an analysis of the competitive relationship between interacting populations within ecosystems (Odum, 1953). In the 1960s and 1970s, the Lotka-Volterra model was used to predict business cycles in macroeconomics by Goodwin (1967) and Samuelson (1971). Since the 1980s, the Lotka-Volterra model has been used to analyze relationships between competing groups and in demand forecasting in the fields of management, industrial engineering, and social science. Karmeshu et al. (1985) and Bhargava (1989) analyzed substitutions of new for old technology using the Lotka-Volterra model. Tsai and Li (2009) used the Lotka-Volterra approach to investigate the dynamics of competition between industrial clusters. A basic two-dimensional Lotka-Volterra model describing two species, $\mathrm{X}$ and $\mathrm{Y}$, includes logistic growth func- 
tion and interaction terms.

$$
\left\{\begin{array}{l}
\dot{X}=\frac{d X}{d t}=X\left(a_{1}-b_{1} X-c_{1} Y\right)=a_{1} X-b_{1} X^{2}-c_{1} X Y \\
\dot{Y}=\frac{d Y}{d t}=Y\left(a_{2}-b_{2} Y-c_{2} X\right)=a_{2} Y-b_{2} Y^{2}-c_{2} Y X
\end{array}\right.
$$

In equation $1, X$ and $Y$ are the total number of species at a given time. The coefficients $\alpha_{i}$ and $b_{i}$ in the equation show the effect of the independent growth of species (that is, growth that is not affected by other species); the coefficients $c_{i}$ reflect an interaction effect with other species. The higher the absolute value of the coefficients $c_{i}$, the greater the magnitude of interaction effect between both species. In contrast, as the absolute value of the coefficients $c_{i}$ approaches 0 , the magnitude of interaction effect decreases.

The Lotka-Volterra model is a continuous time system, but historical data is discrete time in nature. This heterogeneity is a constraint in parameter estimation; therefore, the continuous Lotka-Volterra model represented in equation 1 needs to be transformed into a discrete form if discrete time historical data is used to estimate parameters. Leslie (1957) converted a continuous Lotka-Volterra model to a discrete form as follows.

$$
\left\{\begin{array}{l}
X(t+1)=\frac{\alpha_{1} X(t)}{1+\beta_{1} X(t)+\gamma_{1} Y(t)} \\
Y(t+1)=\frac{\alpha_{2} Y(t)}{1+\beta_{2} Y(t)+\gamma_{2} X(t)}
\end{array}\right.
$$

In equation $2, X(\mathrm{t}+1)$ and $Y(\mathrm{t}+1)$ indicate the total number of species at time $\mathrm{t}+1$ where $X(\mathrm{t})$ and $Y(\mathrm{t})$ stand for the total number of species at time $\mathrm{t}$. The most popular classical method for estimating the coefficients of the discrete Lotka-Volterra model is the nonlinear least-squares method. In general, the parameter estimation of nonlinear equations requires the predetermined initial value of the coefficient. The Levenberg-Marquardt algorithm is widely used to solve the nonlinear problem; its high precision enables one to estimate the initial value. This algorithm can estimate a more robust solution, since the method of estimating the damping parameter is added to the Gauss-Newton algorithm (Marquardt, 1963). The transformation of parameters is represented by Leslie (1957) as follows.

$$
a_{i}=\ln \alpha_{i}, b_{i}=\frac{\beta_{i} \ln \alpha_{i}}{\alpha_{i}-1}, c_{i}=\frac{\gamma_{i} \ln \alpha_{i}}{\alpha_{i}-1}
$$


Odum (1953) suggested using the signs of the interaction coefficients $c_{i}$ to identify a competitive relationship between two species within an ecosystem. Modis (1999) applied this logic in an analysis of the relationship between two competing technologies in the market. The signs of the interaction coefficients $c_{i}$ and $\gamma_{i}$ are identical because the sign of $\ln \frac{\ln \alpha_{i}}{\alpha_{i}-1}$ is always positive when $\alpha_{i}>0$ and $\alpha_{i} \neq 0$ (Zhang $\&$ Lam, 2013). The signs of the interaction coefficients $c_{i}$ and $c_{2}$ yield six types of competitive relationship (table 1).

Table 1. Six Types of Competitive Relationship

\begin{tabular}{c|c|c|l}
\hline$C_{1}$ & $C_{2}$ & Type & \multicolumn{1}{c}{ Explanation } \\
\hline+ & + & pure competition & The growth of both species is interrupted by the other. \\
\hline+ & - & predator-prey & One species is direct food for other species. \\
\hline- & - & mutualism & $\begin{array}{l}\text { A symbiosis between two species, or a win-win situation, } \\
\text { is achieved. }\end{array}$ \\
\hline- & 0 & commensalism & $\begin{array}{l}\text { A parasitic relationship exists between two species. One } \\
\text { species benefits from the other species, which grows } \\
\text { independently. }\end{array}$ \\
\hline+ & 0 & amensalism & $\begin{array}{l}\text { One species suffers from the other species, which grows } \\
\text { independently. }\end{array}$ \\
\hline 0 & 0 & neutralism & No interaction whatsoever occurs. \\
\hline
\end{tabular}

Source: Modis, 1999.

The predator-prey relationship between industrial clusters indicates that one cluster has a competitive advantage over the other cluster. Mutualism represents a symbiotic relationship between two industrial clusters, and pure competition entails the opposite.

\section{The Three-Dimensional Lotka-Volterra Model}

Adding new species $\mathrm{Z}$ and additional interaction coefficients can transform the Lotka-Volterra model into a three-dimensional model. The advantage of using a three-dimensional Lotka-Volterra model is that the competitive dynamics between three clusters can be analyzed (Bischi \& Tramontana, 2009). Since the early 2010s, studies have used this model to analyze three-dimensional competition in the market. For instance, Lakka, Michalakelis, Varoutas, and Martakos (2013) explored competition between Linux, Mac OS, and Windows in the operating systems market using a three-dimensional Lotka-Volterra model. Chang, Li, and Kim (2011) 
found that a three-dimensional Lotka-Volterra model has significantly higher accuracy than the extended Bass model in forecasting the number of subscribers in a saturated mobile phone market. The three-dimensional Lotka-Volterra model is expressed as follows.

$$
\left\{\begin{array}{l}
\dot{X}=\frac{d X}{d t}=X\left(a_{1}-b_{1} X-c_{1} Y-d_{1} Z\right)=a_{1} X-b_{1} X^{2}-c_{1} X Y-d_{1} X Z \\
\dot{Y}=\frac{d Y}{d t}=Y\left(a_{2}-b_{2} Y-c_{2} X-d_{2} Z\right)=a_{2} Y-b_{2} Y^{2}-c_{2} X Y-d_{2} Y Z \\
\dot{Z}=\frac{d Z}{d t}=Z\left(a_{3}-b_{3} Z-c_{3} X-d_{3} Y\right)=a_{3} Z-b_{3} Z^{2}-c_{3} X Z-d_{3} Y Z
\end{array}\right.
$$

In equation $4, X, Y$ and $Z$ are the total number of species at a given time. The new species $Z$ introduces the interaction coefficients $d_{i}$. The transformation from continuous equations to discrete form is as follows.

$$
\left\{\begin{array}{l}
X(t+1)=\frac{\alpha_{1} X(t)}{1+\beta_{1} X(t)+\gamma_{1} Y(t)+\delta_{1} Z(t)} \\
Y(t+1)=\frac{\alpha_{2} Y(t)}{1+\beta_{2} Y(t)+\gamma_{2} X(t)+\delta_{2} Z(t)} \\
Z(t+1)=\frac{\alpha_{3} Z(t)}{1+\beta_{3} Z(t)+\gamma_{3} X(t)+\delta_{3} Y(t)}
\end{array}\right.
$$

In equation $5, X(t+1), Y(\mathrm{t}+1)$ and $Z(t+1)$ indicate total number of species at time $\mathrm{t}+1$ where $X(t), Y(t)$ and $Z(t)$ stand for total number of species at time t. Coefficients of the model are estimated using the same nonlinear least-squares method. The transformation of parameters is as follows.

$$
a_{i}=\ln \alpha_{i}, b_{i}=\frac{\beta_{i} \ln \alpha_{i}}{\alpha_{i}-1}, c_{i}=\frac{\gamma_{i} \ln \alpha_{i}}{\alpha_{i}-1}, d_{i}=\frac{\delta_{i} \ln \alpha_{i}}{\alpha_{i}-1}
$$

The competitive relationship between three species may also be broken down into the same six types presented in table 1 . The difference is that the competitive relationship in the three-dimensional Lotka-Volterra model is determined by the signs of $c_{i}$ and $d_{i}$. The signs of the interaction coefficients $d_{i}$ and $\delta_{i}$ are also identical.

\section{Equilibrium Analysis of the Three-Dimensional Lotka-Volterra Model}

The equilibrium point of the three-dimensional Lotka-Volterra model is deter- 
mined by solving the following equation.

$$
\left\{\begin{array}{l}
\dot{X}=\frac{d X}{d t}=X\left(a_{1}-b_{1} X-c_{1} Y-d_{1} Z\right)=a_{1} X-b_{1} X^{2}-c_{1} X Y-d_{1} X Z=0 \\
\dot{Y}=\frac{d Y}{d t}=Y\left(a_{2}-b_{2} Y-c_{2} X-d_{2} Z\right)=a_{2} Y-b_{2} Y^{2}-c_{2} X Y-d_{2} Y Z=0 \\
\dot{Z}=\frac{d Z}{d t}=Z\left(a_{3}-b_{3} Z-c_{3} X-d_{3} Y\right)=a_{3} Z-b_{3} Z^{2}-c_{3} X Z-d_{3} Y Z=0
\end{array}\right.
$$

The equilibrium point is the value satisfying the simultaneous equation 7 , and it is calculated as equation 8 , where $(\mathrm{X}, \mathrm{Y}, \mathrm{Z}) \neq(0,0,0)$.

$$
\left\{\begin{array}{l}
X=\frac{a_{1}-c_{1} Y-d_{1} Z}{b_{1}} \\
Y=\frac{a_{2}-c_{2} X-d_{2} Z}{b_{2}} \\
Z=\frac{a_{3}-c_{3} X-d_{3} Y}{b_{3}}
\end{array}\right.
$$

The boundary of fields converge to the equilibrium point, and it is determined by the following conditions.

$$
\left\{\begin{array}{l}
\text { if } X>\frac{a_{1}-c_{1} Y-d_{1} Z}{b_{1}} \text {, then } \frac{d X}{d t}<0 \\
\text { if } Y>\frac{a_{2}-c_{2} X-d_{2} Z}{b_{2}} \text {, then } \frac{d Y}{d t}<0 \\
\text { if } Z>\frac{a_{3}-c_{3} X-d_{3} Y}{b_{3}}, \text { then } \frac{d Z}{d t}<0
\end{array}\right.
$$

The trajectory converges to the equilibrium point in the three-dimensional space that satisfies all three conditions presented in equation 9.

\section{Data Collection}

New orders, number of ships completed, and order backlogs are the three most popular performance indicators of the shipbuilding industry. To analyze the national competitive dynamics of China, Japan, and South Korea in the global shipbuilding industry, we used annual shipbuilding completion data. We note that contract termination and cancelation have been increased since the payment system was changed during the global financial crisis of 2008 and that final demand is not accurately reflected in the number of new orders. Therefore, actual demand can be 
overestimated if one uses new orders as a proxy for shipbuilding demand. This study uses the annual data documenting the number of ships completion by China, Japan, and South Korea, for the 1987-2015 period (this the period that data is available for). Data was collected from the "Shipbuilding Statistics Data" of the Korean Offshore and Shipbuilding Association and the "Shipbuilding Statistics" of the Shipbuilder's Association of Japan (SAJ). We followed the procedure of Lloyd's statistics, which only includes shipbuilding data above 100GT (gross tonnage), in collecting our statistics. Therefore, our data only includes ships over 100GT. Table 2 shows the dominant position of Japan, Korea, and China in the global shipbuilding market.

Table 2. Number of Ships Built by Country in 2015.

\begin{tabular}{c|c|c}
\hline Country & Total (GT) & Proportion \\
\hline China & $25,275,424$ & $37.24 \%$ \\
\hline South Korea & $23,756,983$ & $35.00 \%$ \\
\hline Japan & $12,899,210$ & $19.00 \%$ \\
\hline Other Countries & $5,945,285$ & $8.76 \%$ \\
\hline
\end{tabular}

Source: UNCTAD, 2018.

\section{RESULTS AND DISCUSSION}

\section{Parameter Estimation}

We estimate the parameters of the three-dimensional discrete Lotka-Volterra model using the Levenberg-Marquardt algorithm. High values for the estimated $\mathrm{R}^{2}$ of Japan, South Korea, and China indicate that a three-dimensional discrete Lotka-Volterra model fits the data. Low values of mean absolute percentage error (MAPE) for Japan and South Korea reflect the high forecasting accuracy of the model, but China's value is not as low as for the other countries. The parameter estimation results are presented in table 3 . 
Table 3. Estimated Parameters of the Three-Dimensional Discrete Lotka-Volterra Model

\begin{tabular}{l|c|c|c|c|c|c}
\hline & \multicolumn{4}{|c|}{ Parameter } & \multirow{2}{*}{$\mathbf{R}_{i}$} & MAPE \\
\cline { 2 - 7 } & $\boldsymbol{\alpha}_{i}$ & $\boldsymbol{\beta}_{i}$ & $\gamma_{i}$ & $\boldsymbol{\delta}_{\mathbf{i}}$ & & \\
\hline Japan $(i=1)$ & 1.0463 & $4.0072 \mathrm{E}-06$ & $-7.4706 \mathrm{E}-06$ & $8.4413 \mathrm{E}-06$ & 0.964 & 6.843 \\
\hline South Korea $(i=2)$ & $8.3241 \mathrm{E}-01$ & $1.6819 \mathrm{E}-05$ & $-3.6413 \mathrm{E}-05$ & $3.5430 \mathrm{E}-07$ & 0.972 & 9.346 \\
\hline China $(i=3)$ & $5.8045 \mathrm{E}-01$ & $1.7444 \mathrm{E}-05$ & $-2.3151 \mathrm{E}-05$ & $-1.8553 \mathrm{E}-05$ & 0.970 & 21.688 \\
\hline
\end{tabular}

Shipbuilding completion estimates and observations for Japan over the 19882014 period are illustrated in figure 1 .

Figure 1. Number of Ships Estimated to Be Completed vs. Number of Ships Completed in Japan, 1988-2015.

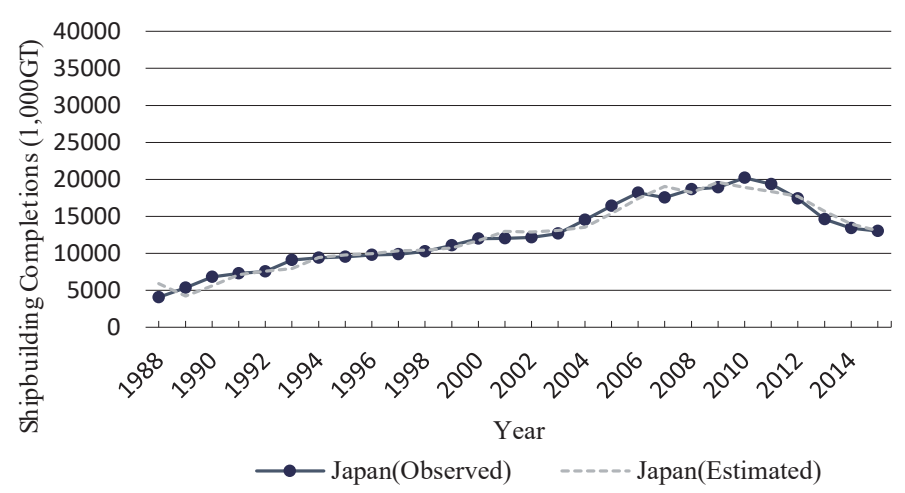

The number of ships Japan has built increased continually from 1988 to 2010 but has decreased since 2010. Figure 1 shows a stationary pattern in the number of ships Japan has built. That the estimates and the observations are nearly identical indicates that the estimated model fully reflects the fluctuations in number of ships completed in Japan.

The shipbuilding completion estimates and observations for South Korea for the 198-2014 period are illustrated in figure 2 . 
Figure 2. Number of Ships Estimated to Be Completed vs. Number of Ships Completed in South Korea, 1988-2015

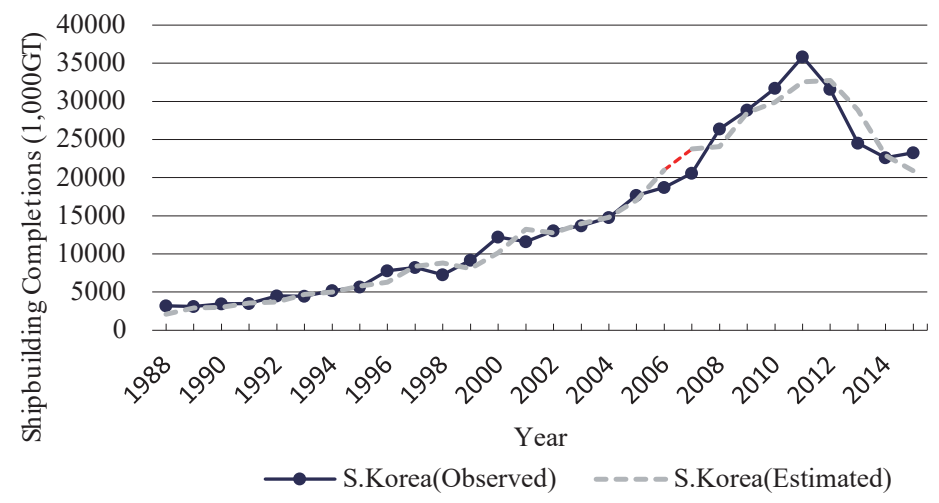

South Korea's overtook Japan in the mid-2000s, as the number of ships it has built each year has grown steeply since the 1990s. Figure 2 shows that South Korea reached its peak in 2011 and that the number of ships it completed declined steeply until 2014. Overall, the time series is less stationary than that of Japan's, and the MAPE value is a little higher than Japan's. Estimates are similar to observations and reflect fluctuations in number of ships built after the financial crisis of 2008.

The shipbuilding completion estimates and observations for China for the 19882014 period are illustrated in figure 3.

Figure 3. Number of Ships Estimated to Be Completed vs. Number of Ships Completed in China, 1988-2015

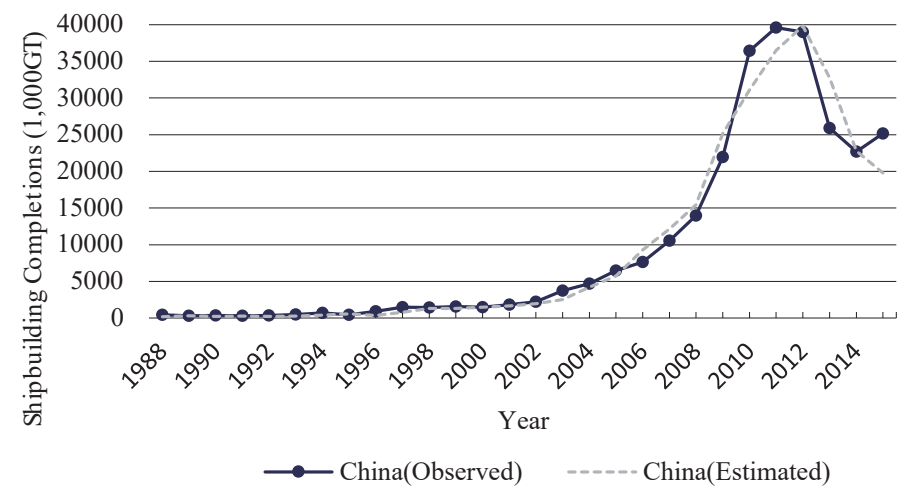


Since the mid-2000s, the number of ships China has built has grown steeply. In particular, China experienced dramatic growth from 2008 to 2010 and reached its peak in 2011. After 2011, China shows a similar pattern to that of South Korea.

Overall, out of the three countries, Japan's time series pattern is the most stationary, even despite significant changes in the competitive composition of the global shipbuilding industry that have occurred the 2000s. The sudden growth of South Korea's and China's shipbuilding industry in the mid-2000s diverted shipbuilding demands from Japan to South Korea and China, and the competitive composition of the global shipbuilding industry became more complex.

\section{Competitive Relationship Analysis}

The parameters in equation 6 are derived by substituting the parameters of the three-dimensional discrete Lotka-Volterra model estimated in equation 5. Most of the previous studies that have attempted to analyze competitive relationships only report the competitive relationship of the last year of a given period (Kim, Lee \& Ahn, 2006; Tsai \& Li, 2009; Chiang \& Wong, 2011); however, competitive relationships change over time and it is worth exploring this change (Zhang \& Lam, 2013). Modis (1999) analyzed whether there was a significant change in the competitive relationship between stocks and bonds during the 1997 Asian financial crisis. Lee, Lee, and Oh (2005) found that this financial crisis changed the competitive relationship between the Korean stock market's KOSDAQ and KOSPI. Our study carries out an year-by-year analysis of the changing

Figure 4. Number of Ships Completed in China, South Korea, and Japan, 2006-15

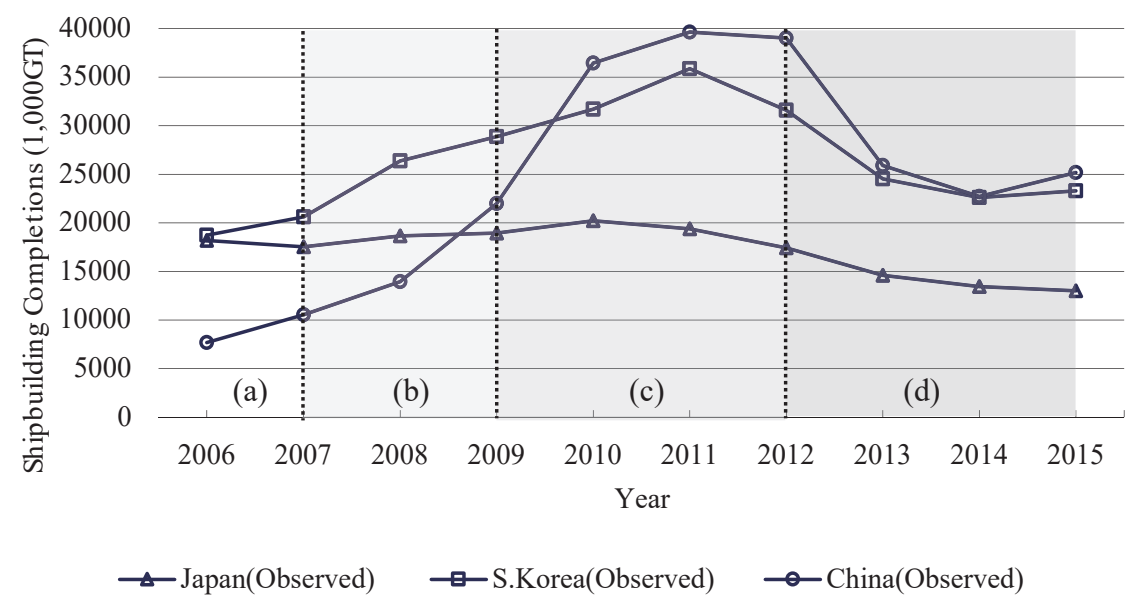


competitive relationships between Japan, South Korea and China that ensued in the wake of the financial crisis of 2008. Time series changes for number of ships built in the three countries are presented in figure 4 . Table 4 presents the results of the analysis of these competitive relationships.

Table 4. Comparison of Japan's, South Korea's, and China's Signs of c_i and d_i, 2006-15

\begin{tabular}{|c|c|c|c|c|c|c|c|c|c|}
\hline & \multicolumn{3}{|c|}{ Japan } & \multicolumn{3}{|c|}{ South Korea } & \multicolumn{3}{|c|}{ China } \\
\hline & $C_{1}$ & $d_{1}$ & $\mathbf{R}^{2}$ & $c_{2}$ & $d_{2}$ & $\mathbf{R}^{2}$ & $C_{3}$ & $d_{3}$ & $\mathbf{R}^{2}$ \\
\hline 2006 & - & - & 0.962 & - & - & 0.969 & + & - & 0.979 \\
\hline 2007 & - & - & 0.957 & - & + & 0.974 & - & - & 0.985 \\
\hline 2008 & - & - & 0.962 & - & - & 0.978 & - & - & 0.990 \\
\hline 2009 & - & + & 0.962 & - & - & 0.983 & + & - & 0.995 \\
\hline 2010 & - & + & 0.968 & - & - & 0.983 & + & - & 0.998 \\
\hline 2011 & - & + & 0.971 & - & - & 0.986 & + & - & 0.995 \\
\hline 2012 & - & + & 0.968 & - & - & 0.982 & - & - & 0.987 \\
\hline 2013 & - & + & 0.965 & - & - & 0.973 & - & - & 0.984 \\
\hline 2014 & - & + & 0.964 & - & - & 0.974 & - & - & 0.980 \\
\hline 2015 & - & + & 0.964 & - & + & 0.972 & - & - & 0.970 \\
\hline
\end{tabular}

Estimated $\mathrm{R}^{2}$ values in every year and country indicate the high explanatory power of the model. The changes in the nature of the competitive relationships over time are presented in table 5.

Table 5. Changes in the Nature of the Competitive Relationships between Japan, South Korea, and China, 2006-15

\begin{tabular}{c|c|c|c}
\hline \multirow{2}{*}{} & \multicolumn{3}{|c}{ Competitive Relationship } \\
\cline { 2 - 4 } & $\begin{array}{c}\text { Japan- } \\
\text { South Korea }\end{array}$ & South Korea-China & Japan-China \\
\hline $\mathbf{2 0 0 6}$ & mutualism & mutualism & predator-prey (predator: Japan) \\
\hline $\mathbf{2 0 0 7}$ & mutualism & predator-prey (predator: China) & Mutualism \\
\hline $\mathbf{2 0 0 8}$ & mutualism & mutualism & mutualism \\
\hline $\mathbf{2 0 0 9}$ & mutualism & mutualism & pure competition \\
\hline $\mathbf{2 0 1 0}$ & mutualism & mutualism & pure competition \\
\hline $\mathbf{2 0 1 1}$ & mutualism & mutualism & pure competition \\
\hline $\mathbf{2 0 1 2}$ & mutualism & mutualism & predator-prey (predator: China) \\
\hline $\mathbf{2 0 1 3}$ & mutualism & mutualism & predator-prey (predator: China) \\
\hline $\mathbf{2 0 1 4}$ & mutualism & mutualism & predator-prey (predator: China) \\
\hline $\mathbf{2 0 1 5}$ & mutualism & predator-prey (predator: China) & predator-prey (predator: China) \\
\hline
\end{tabular}


We note some interesting patterns in the changing competitive relationships between the three countries since 2006. First, South Korea's relationship with Japan has been characterized by mutualism; its relationship with China has also likewise been characterized by mutualism, except in 2007 and 2015, when China had a competitive advantage over South Korea. Second, the competitive relationship between Japan and China has changed dynamically. These changes can be divided into four subperiods. Initially in 2006 (period a in figure 6), Japan had a competitive advantage over China. This competitive relationship became a mutualistic one after 2006 (period b in figure 6) and to purely competitive one after the financial crisis of 2008 (period $\mathrm{c}$ in figure 6). We note that in period $\mathrm{c}$, the number of ships build by China increased dramatically. The decline in the international trade volume due to the global economic slump after the 2008 financial crisis affected the profitability of the shipping industry and led to a decline in demand for vessels, resulting in an “order cliff” (Park \& Koo, 2017). In particular, shipbuilding financing was frozen, leading to a sharp drop in ship prices across all ship types and creating a market for low-priced ships. Although the Chinese shipbuilding industry was also been affected by the 2008 financial crisis in the short term, it has steadily increased its order backlog by targeting the low-cost shipbuilding market, which has expanded since the financial crisis, receiving government support and having low labor costs (Bank of Korea, 2010). Since 2012 (period d in figure 6), there has been a time lag due to the financial crisis. In period d, the three countries' shipbuilding industries simultaneously declined, although China secured a competitive advantage over Japan. This suggests that Japan has suffered directly as a result of China in the global shipbuilding industry. South Korea's competitive relationship with the two other countries, however, has not significantly changed in. In the wake of the financial crisis in 2008, China's labor-intensive strategy thus seems to have gradually earned it a competitive advantage over Japan's technology-intensive strategy. Beginning with period c, the number of ships China built surpassed that of Japan and South. These findings indicate that the global market environment favored China's labor-intensive strategy in the period from the financial crisis of 2008 to 2015.

\section{Equilibrium Analysis}

We conducted an equilibrium analysis to determine whether there is a stable equilibrium point in the global shipbuilding industry. The value satisfying equation 8 is an equilibrium point excluding origin, and not all the Lotka-Volterra models have an equilibrium point (Edelstein-Keshet, 1988). We present the surface normal 
form of the three-dimensional space in order to explore the existence of an equilibrium point intuitively. At the same time, we explore whether the space that satisfies the condition of equation 9 exists in the three-dimensional space. Figure 5 illustrates a dynamic system based on the surface normal form of an equilibrium analysis.

Figure 5. Dynamic System Based on Surface Normal Form of Estimated Simultaneous Equations

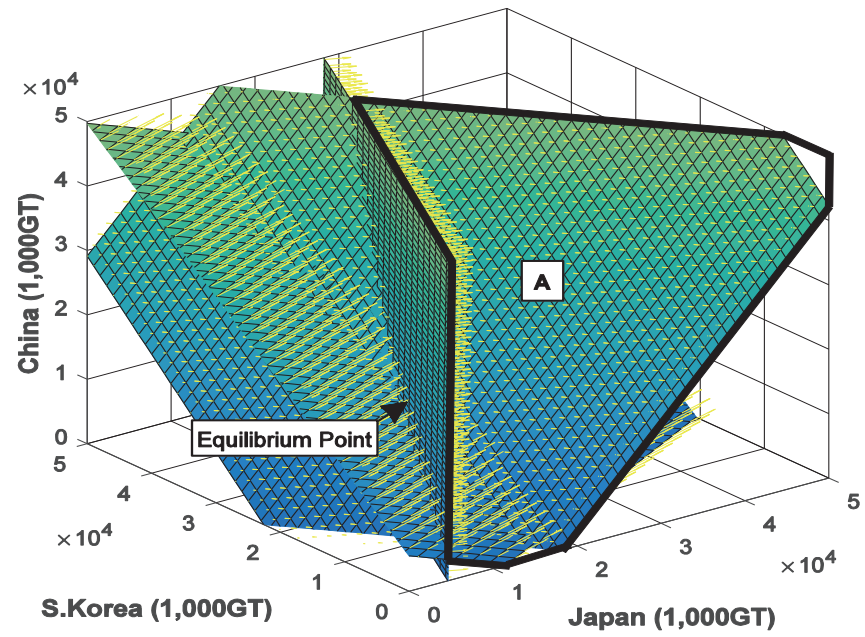

Figure 5 indicates that an equilibrium point exists for this model in the three-dimensional space. Space A, illustrated in figure 5, satisfies the conditions of equation 9 and estimates converge toward an equilibrium point within it. Table 6 presents the equilibrium point, the solution of equation 8 .

Table 6. Equilibrium Point (1,000 GT)

\begin{tabular}{c|c|c|c}
\hline & Japan & South Korea & China \\
\hline Equilibrium Point & 14338.7038 & 20720.6463 & 17015.7507 \\
\hline
\end{tabular}

The number of ships completed by Japan, South Korea, and China converge on the equilibrium point under the current circumstances. In order to investigate the trajectory that would be required to reach the equilibrium point, we conducted a numerical simulation using the Runge-Kutta fourth-order method. Figure 6 shows 
both the observed trajectory for the number of ships built by Japan, South Korea, and China for the 1987-2015 period and the forecasted trajectory starting in 2016.

Figure 6. The Trajectory of Shipbuilding Completion in China, South Korea, and Japan

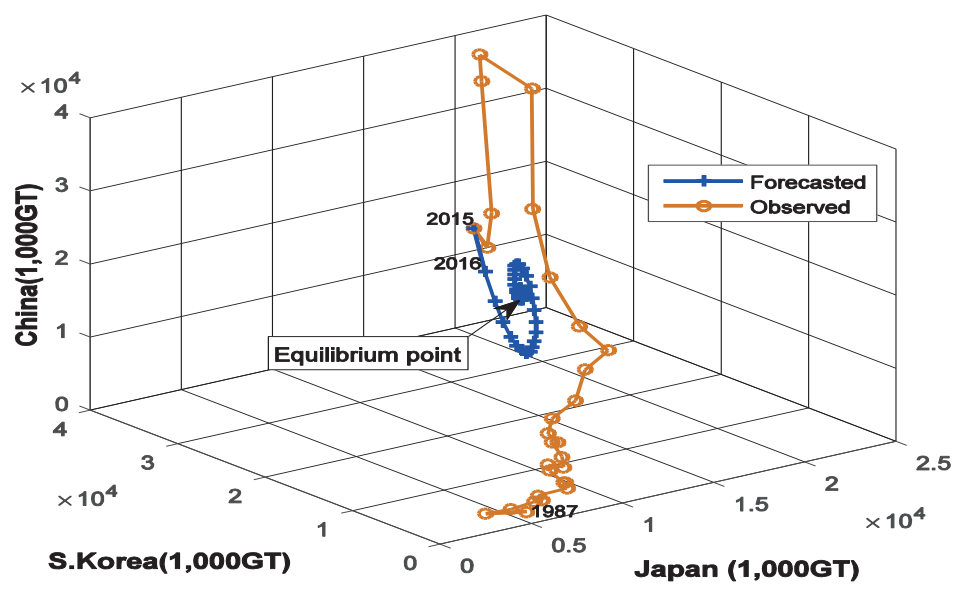

Forecasting the Number of Ships Japan, South Korea, and China Will Build

We compared fluctuations in the number of ships built by Japan, South Korea, and China using the trajectory obtained from the equilibrium analysis. Figure 7 presents the forecasted shipbuilding completions for Japan, South Korea, and China through 2026.

Figure 7. Forecasting Shipping Completion for Three Countries through 2026.

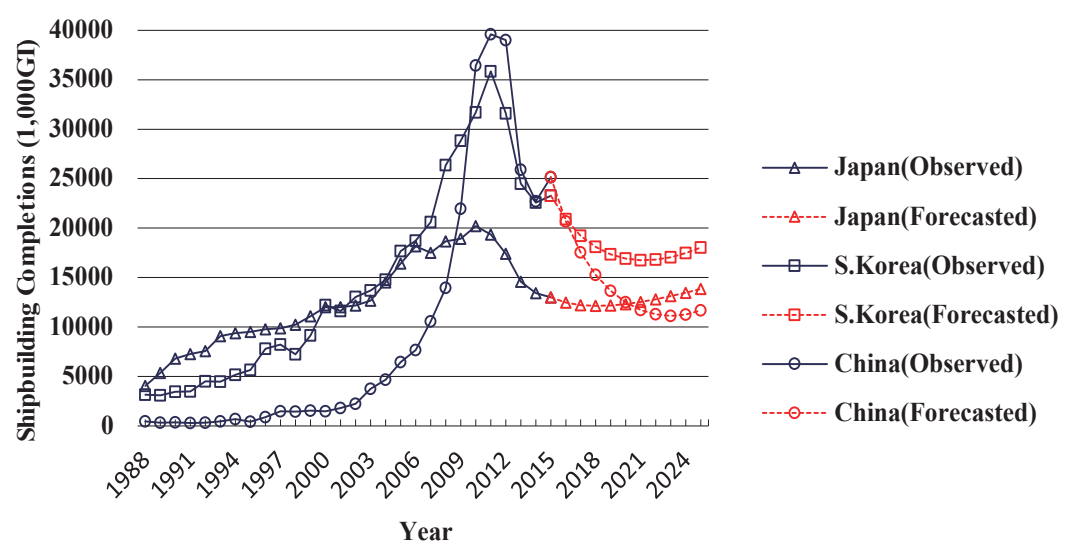


The forecast indicates that South Korea will maintain a relatively high market share; Japan will gradually return to an uptrend and finally overtake China; and China will continue to decline and in the end return to an uptrend.

These findings suggest that technological innovation may be an important factor for competition in the global shipbuilding industry. With its labor-intensive strategy and price competitiveness, China dominated the global market after the financial crisis of 2008; however, simulation results suggest that competitive advantage in the future may not be determined by price competitiveness but by technological superiority. In the near future, therefore, the global shipbuilding industry may be reorganized into a high-tech industry if it adopts a strategic approach research and development rather than focusing mainly on price competitiveness.

\section{CONCLUSIONS}

This study has aimed to investigate dynamic competition between Japan, South Korea, and China in the global shipbuilding industry. We applied a three-dimensional Lotka-Volterra model to track the changes in competitive relationships between the three countries and forecast the number of ships each country will complete by 2026.

The results show that South Korea has maintained relationships with Japan and China that are characterized by mutualism. China's labor-intensive strategy caught up with Japan's technology-intensive strategy in the wake of the 2008 financial crisis, but simulation results suggest that China's labor-intensive strategy may soon lose its price-competitive advantage unless China adopts a technology-intensive strategy. To survive in a hypercompetitive environment, technological innovation will be a key factor, and therefore, in near the future, the global shipbuilding industry may become more technology intensive. These results also provide evidence that can help in making decisions on how to distribute resources and abilities in order to secure an advantage over the competition.

The findings of this study suggest that national industrial development policies such as financial or tax support should be focused primarily on technological innovation in the shipbuilding industry rather than cost reduction. For example, the South Korean government creating an ecoship fund through the Export-Import Bank of Korea earmarking \$80 million to support research and development in the field of ecoships. Government intervention is important in order if an industry is to reach the social optimum of technological innovation while avoiding market failure (Martin \& Scott, 1998). Owing to the International Maritime Organization's envi- 
ronmental regulations and the wave of Industry 4.0, the global shipbuilding industry is being transformed into a technology-intensive industry. Each country should formulate a strategy focusing more closely on research and development than ever before so that the domestic shipbuilding industry is able to deal with this rapid change in the industrial environment.

This is the first study to explore the changing competitive relationships between three leading countries in the global shipbuilding industry from a dynamic perspective. With a high R-squared value and relatively low MAPE for each country, our study suggests that the three-dimensional Lotka-Volterra model is an appropriate tool with which to describe the dynamic competitive system in the global shipbuilding industry. Since Karmeshu et al. (1985), many researchers have conducted dynamic industry analyses using the Lotka-Volterra model, yet these studies have not covered a large research area. Using an ecological competition model to analyze dynamic competition in industry widens our perspective by expanding the traditional static view of competition. Early researchers such as Samuelson (1971) suggest that the Lotka-Volterra model is a useful way to describe the economy and other social phenomena, as in our study.

Lee et al. (2005) suggest that financial crises can change competitive relationships between economic units. The shipbuilding industry is more sensitive to external shocks than other industries (Pires, Lamb, \& Souza, 2009). As shown in this study, the competitive relationship between China and Japan changed after the financial crisis, and China's labor-intensive strategy became dominant in the market, and therefore, it is possible that the equilibrium point will be changed by other strong external shocks such as another financial crisis. Further research needs to be undertaken to capture this possible change. It is also recommended that shipbuilding technology be divided into energy efficiency improvement technology and convergence with information technology, so as to investigate the impact of these technologies on the competitive composition of the global shipbuilding industry.

\section{REFERENCES}

Bank of Korea. 2010. Trends in and prospects for the shipbuilding industry. Busan: Bank of Korea.

Bischi, G. I., \& Tramontana, F. 2010. Three-dimensional discrete-time Lotka-Volterra models with an application to industrial clusters. Communications in Nonlinear Science and Numerical Simulation, 15(10): 3000-3014. 
Bhargava, S. C. 1989. Generalized Lotka-Volterra equations and the mechanism of technological substitution. Technological Forecasting and Social Change, 35(4): 319-326.

Chang, B. Y., Li, X., \& Kim Y. B. 2014. Performance comparison of two diffusion models in a saturated mobile phone market. Technological Forecasting and Social Change, 86(C): 41-48.

Chiang, S-Y., \& Wong, G-G. 2011. Competitive Diffusion of Personal Computer Shipments in Taiwan. Technological Forecasting and Social Change, 78(3): 526535.

Edelstein-Keshet, L. 1988. Mathematical models in biology. New York: Random House.

Goodwin, R. M. 1967. A growth cycle. In C. H. Feinstein (ed.), Socialism, capitalism, and economic growth (). Cambridge: Cambridge University Press.

Jiang, L., Bastiansen, E., \& Strandenes, S. P. 2013. The international competitiveness of China's shipbuilding industry. Transportation Research: Part E, Logistics and Transportation Review, 60(C): 39-48.

Karmeshu, Bhargava, S. C., \& Jain, V. P. 1985. A rationale for law of technological substitution. Regional Science and Urban Economics, 15 (1): 137-141.

Kim, J., Lee, D-J., \& Ahn, J. 2006. A dynamic competition analysis on the Korean mobile phone market using competitive diffusion model. Computers and Industrial Engineering, 51(1): 174-182.

Korea Development Bank. 2018. Competitiveness between Korea, China, Japan in the Shipbuilding Industry. Seoul: Korea Development Bank Report.

Lakka, S., Michalakelis, C., Varoutas, D., \& Martakos, D. 2013. Competitive dynamics in the operating systems market: Modeling and policy implications. Technological Forecasting and Social Change, 80(1): 88-105.

Lee, S., Lee D., \& Oh, H. 2005. Technological forecasting at the Korean stock market: A dynamic competition analysis using Lotka-Volterra model. Technological Forecasting and Social Change, 72(8): 1044-1057.

Leslie, P. H. 1957. A stochastic model for studying the properties of certain biological systems by numerical methods. Biometrika, 45(1): 16-31.

Lotka, A. J. 1925. Elements of physical biology. Baltimore, MD: Williams and Wilkens.

Marquardt, D. 1963. An algorithm for least-squares estimation of nonlinear parameters. SIAM Journal on Applied Mathematics, 11(2): 431-441.

Martin, S., \& Scott, J. 1998. Market failures and the design of innovation policy. Report prepared for the Working Group on Technology and Innovation Policy, Division of Science and Technology, Organisation of Economic Co-operation 
and Development.

Modis, T. 1999. Technological forecasting at the stock market. Technological Forecasting and Social Change, 62(3): 173-202.

Odum, E. P. 1953. Fundamentals of ecology. Philadelphia: W. B. Saunders Company.

Park, J., \& Koo, M. G. 2017. The origin and evolution of the crisis in the offshore-plant industry in South Korea: Goal ambiguity and governmental politics. Korean Journal of Policy Studies, 32(1): 71-97.

Pires Jr., F., Lamb, T., \& Souza, C. 2009. Shipbuilding performance benchmarking. International Journal of Business Performance Management, 11(3): 216-235.

Samuelson, P. 1971. Generalized predator-prey oscillations in ecological economic equilibrium. Proceedings of the National Academy of Sciences, 68(5): 980-983.

Samuelson, P. 1974. A biological least-action principle for the ecological model of Volterra-Lotka. Proceedings of the National Academy of Sciences, 71(8): 30413044.

Tsai, B.-H., \& Li, Y. 2009. Cluster evolution of IC industry from Taiwan to China. Technological Forecasting and Social Change, 76(8): 1092-1104.

UNCTAD. 2018. UNCTADSTAT database. United Nations Conference on Trade and Development, retrieved on December 6, 2018, from unctadstat.unctad.org/wds/ TableViewer/tableView.aspx.

Zhang, W., \& Lam, J. S. L. 2013. Maritime cluster evolution based on symbiosis theory and the Lotka-Volterra model. Maritime Policy and Management, 40(2): 161-176. 
